\title{
Tissue typing amniotic fluid cells: potential use for detection of contaminating maternal cells
}

\author{
M. NIAZI, D. V. COLEMAN, J. F. MOWBRAY, AND S. BLUNT \\ From the Cytogenetics and Tissue Typing Laboratories, St. Mary's Hospital, London; and \\ the Paediatric Research Unit, Guy's Hospital, London
}

SUMMARY The presence of contaminating maternal cells in amniotic fluid is an important, though infrequent, cause of error in karyotyping the fetus. A method of detecting contaminating maternal cells in amniocentesis specimens by determining the HLA phenotype of the cells of amniotic fluid and the mother is described. Tissue typing of 15 amniocentesis specimens was performed, and in 14 cases the fetal origin of the cells was established. In one case, the results of tissue typing suggested maternal cell contamination, though this had not been suspected from chromosome studies of the amniotic fluid cell cultures. Other possible uses for tissue typing of amniotic fluid specimens for prenatal diagnosis are also described.

In the majority of cases the cells cultured from amniotic fluid are fetal in origin. Occasionally, the amniotic fluid is contaminated with maternal cells which, during the culture process, overgrow the fetal cells and lead to errors in chromosome analysis. Ferguson-Smith (1975) reported the misdiagnosis of 3 of 617 amniotic samples as a result of maternal contamination. The karyotypes of the cultured cells were reported as those of a normal female, but at birth 2 of the neonates were normal males and the third was a female with Down's syndrome.

Though errors of diagnosis as a result of maternal cell contamination occur rarely (Nadler, 1972; Milunsky, 1973), they are of considerable importance and two precautionary measures have been recommended (Polani, 1971; Ferguson-Smith and Ferguson-Smith, 1976). One of these involves chromosome analysis of several primary cultures of amniotic fluid, and the other relies upon the identification of parental chromosome polymorphism in the fetal karyotype. Both techniques have their drawbacks. The first is time consuming and delays reporting, and the usefulness of the second is limited by the quality of the preparation (Lawler and Reeves, 1976). We describe here another possible method of detecting maternal cell contamination by tissue typing cells of amniotic fluid and the mother.

\section{Materials and methods}

Samples of amniotic fluid obtained between the 16th and 18th week of pregnancy for prenatal diagnosis

Received for publication 14 June 1978 were cultured to provide a source of cells for cytogenetic studies and tissue typing. At least two tissue culture flasks (Falcon 3013) were prepared from each primary culture, one of which was used for chromosome analysis and the other for tissue typing. The cells in this flask were tripsinised and plated out into the wells of Falcon Terasaki microtest plates at a concentration of 300 to 400 cells per well. The plates were incubated at $37^{\circ} \mathrm{C}$ in a humidified atmosphere containing $5 \%$ carbon dioxide and $95 \%$ air until confluent monolayers were formed; this usually took between 24 and 48 hours. The monolayers were washed with Hank's balanced salt solution, and the plates were flooded with low density paraffin oil.

Using a battery of human antisera of different specificities, the human leucocyte antigens of the cell monolayers in the wells were determined using a modification of the cytotoxic method of Terasaki (1970). $2 \mu \mathrm{l}$ antiserum were added to the wells and the plates were incubated at $37^{\circ} \mathrm{C}$ for one hour. This was followed by the addition of $2 \mu \mathrm{l}$ rabbit serum as complement to each well and the plates were further incubated for one hour. The cells were stained with $5 \%$ eosin, fixed with formaldehyde, and the percentage of dead cells determined using an inverted phase microscope. Cytotoxic activity of a test antiserum was measured as a significant increased killing of cells over that in negative controls.

Blood samples obtained from the parents were tissue typed by the lymphocytotoxic method and the fetal origin of the amniotic fluid cells was established by showing the presence of HLA haplotypes from 
both parents on the cultured cells. In three cases the HLA antigens of amniotic cells were also compared with those detected on the lymphocytes of the cord blood. As we only encountered possible maternal contamination in one specimen, suspensions of amniotic fluid cells and maternal skin fibroblasts were prepared, mixed in equal proportions, and grown in the wells of the microtest plates to provide a model for testing the sensitivity of the method.

\section{Results}

The results of tissue typing are shown in the Table.

The presence of an HLA haplotype of each parent indicated the fetal origin of the amniotic fluid cells in 14 of the 15 amniocenteses analysed. The tissue type of the amniotic fluid cells was identical to that of the lymphocytes of the cord blood in the 3 cases investigated.

In the 3 cases where the HLA antigens on mixed cell cultures were determined, both maternal and fetal antigens were detected. The fraction of cells killed with specific antisera varied from 50 to $100 \%$.

In case 2, where the HLA antigens on maternal lymphocytes and amniotic fluid cells were identical, the fetal origin of the amniotic fluid cells could not be established from analysis of HLA phenotypes.

In case 10 , both maternal $B$ locus antigens 12 and 14 were detected on the cells grown from amniotic fluid and a low percentage of cells were killed by antibody against B14. These findings suggest that maternal contamination may have occurred and that the cultures contained both fetal cells with the phenotype $A 1,-; B 8,12$, and maternal cells with the phenotype A11, -; B12, 14.

\section{Discussion}

Our results show that HLA antigens are clearly expressed on cells grown from amniotic fluid at ang early stage of pregnancy. We have found that the cytotoxic method of detecting these antigens is simple to perform and easy to read, provided tha员 good monolayers are obtained in the wells of the microtest plates and the following precautions are taken. The plates should be incubated for at leas? 48 hours after distributing the cells in the microwells $\overrightarrow{\vec{\omega}}$ and the monolayers should be washed thoroughlye to remove all traces of fetal bovine serum befor adding the specific antisera.

In the one case where the HLA phenotype of the्ष amniotic fluid cells was indistinguishable from that of the maternal cells, the mother had only onedetectable HLA antigen at each locus (A2 and B15)을 both of which were also present in the father. As a result, analysis of the parental HLA phenotype could not be used to determine the source of the cells in the amniotic fluid. Though this can be inter preted as a limitation of the method, such an occura rence in unrelated parents is a rare event.

We observed varying degrees of cell killing in the mixed cell culture, which appeared to reflect the proportion of fetal and maternal cells in the cultureo Analysis of our results showed that antigens common to mother and fetus were detected on all cells, while्द्य those specific to mother or fetus were only found or some cells.

In case 10 , maternal cell contamination was no $\overrightarrow{\overrightarrow{0}}$ suspected from chromosome studies. Analysis of 15 spreads showed a normal male karyotype indicating that tissue typing may be a more sensitive technique

Table HLA antigens detected in parents, amniotic fluid, and cord blood

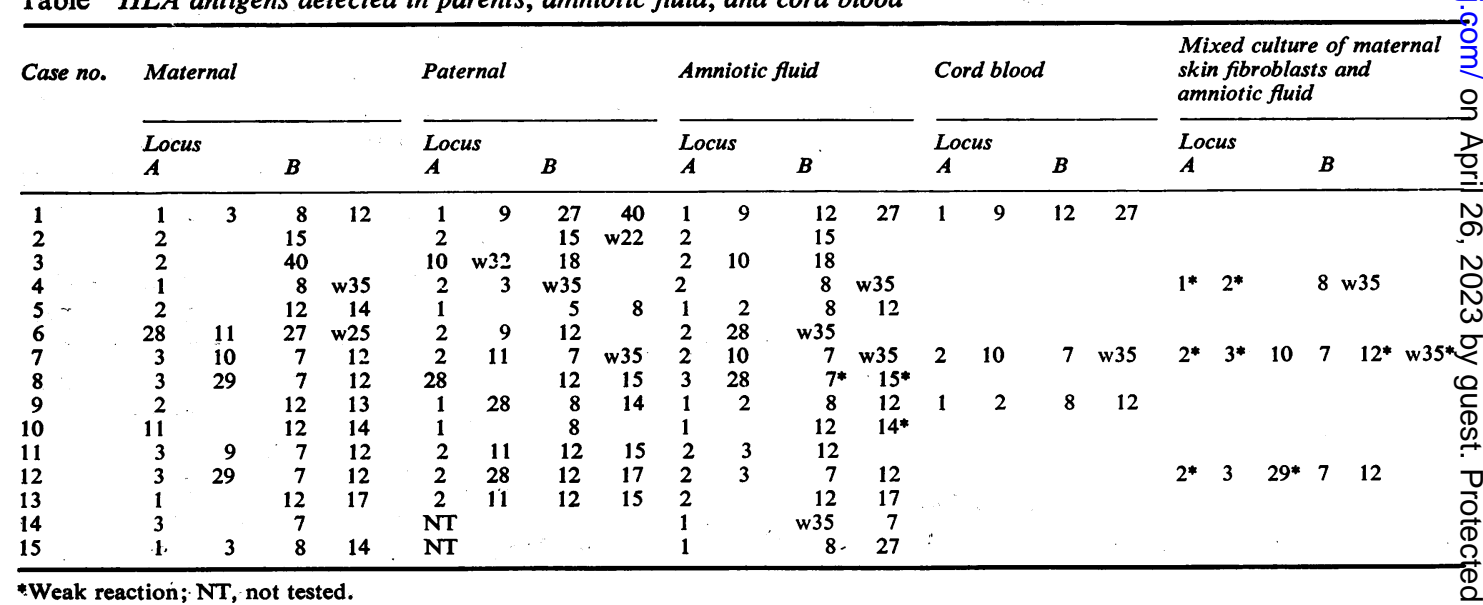

*Weak reaction; NT, not tested. 
than karyotyping for detecting maternal cells in the fluid. We suggest that tissue typing of amniotic fluid cells could be used in a routine cytogenetic laboratory as an alternative to analysis of several primary cultures or demonstration of familial chromosome polymorphism in those cases where maternal contamination is suspected. Another advantage of tissue typing is that it offers the possibility of eliminating contaminating maternal cells from the culture. This could be achieved by applying to the cultured cells specific antisera directed against the maternal haplotype not present on the fetal cells.

The HLA phenotype is a readily identifiable genetic marker which can be detected on all nucleated cells and, therefore, could be useful in prenatal diagnosis. If linkage between an inherited abnormality and HLA were known, tissue typing the amniotic fluid cells would provide a method of detecting an affected fetus in utero. Furthermore, because of the genetic polymorphism of the HLA system, tissue typing of amniotic fluid cells could be used for prenatal paternal ascertainment. Thus, tissue typing of fetal cells has the potential for a wider application in the field of antenatal diagnosis.

We thank Mrs H. Harris and Miss S. Hollowell, St. Mary's Hospital, for technical assistance, and Dr C. C. Entwhistle, Deputy Director, National Tissue
Typing Reference Laboratory, Britstol, for providing the specific antisera used in this study.

This work was supported by a grant from the Joint Standing Research Committee of St. Mary's Hospital.

\section{References}

Ferguson-Smith, M. A. (1975). Progress Report on Prenatal Diagnosis in the West of Scotland, 1969-1975.

Ferguson-Smith, M. A., and Ferguson-Smith, M. E. (1976). Screening for foetal chromosome aberrations in early pregnancy. Journal of Clinical Pathology, 29, Suppl. 10, 165-176.

Lawler, S. D., and Reeves, B. R. (1976). Chromosome studies in man: past achievements and recent advances. Journal of Clinical Pathology, 29, 569-582.

Milunsky, A. (1973). The Prenatal Diagnosis of Hereditary Disorders, chap. 11, p. 21. Charles C. Thomas, Springfield, Illinois.

Nadler, H. L. (1972). Prenatal detection of genetic disorders. Advances in Human Genetics, 3, 1-37.

Polani, P. E. (1971). Prenatal cytological recognition of sexlinked and chromosomal abnormalities. Journal of Obstetrics and Gynaecology of the British Commonwealth, 78, 1024-1030.

Terasaki, P. I. (1970). Manual of Tissue Typing Technique. Transplantation and Immunology Branch, National Institutes of Health, Bethesda, Maryland.

Requests for reprints to Dr D. V. Coleman, Cytogenetics and Tissue Typing Laboratories, St. Mary's Hospital, Praed Street, London W2 1NY. 